\title{
Idiopathic hypertrophic cranial pachymeningitis mimicking multiple meningiomas: case report and review of the literature
}

\author{
M. Deprez ${ }^{1}$, J. Born ${ }^{2}$, C. Hauwaer ${ }^{3}$, B. Otto ${ }^{4}$, M. Reznik ${ }^{1}$ \\ ${ }^{I}$ Department of Neuropathology, Tour de Pathologie-B-35, CHU, B-4000 Sart-Tilman-Liège, Belgium \\ ${ }^{2}$ Department of Neurosurgery, CHR, Liège, Belgium \\ ${ }^{3}$ Department of Internal Medicine, CHU, Liège, Belgium \\ ${ }^{4}$ Department of Radiology, CHR, Liège, Belgium
}

\begin{abstract}
A case of idiopathic hypertrophic cranial pachymeningitis with an unusual and misleading manifestation is reported. Computed tomography scan, angiographic and magnetic resonance imaging findings were suggestive of multiple meningeal neoplasms and a correct diagnosis was made only after meningeal biopsy. This 44-yearold patient had a previous history of an ill-defined systemic disorder associating episcleritis, erythroderma nodosa and multiple peripheral arthritis. We review previous reports of idiopathic cranial pachymeningitis with emphasis on radiological investigation techniques, histopathology and possible dysimmune mechanisms of pathogenesis.
\end{abstract}

Keywords : Dura mater ; Meningitis ; Tumor

\section{Introduction}

Idiopathic hypertrophic cranial pachymeningitis (IHCP) is a chronic and progressive inflammatory disease that usually results in a diffuse thickening of the dura mater. It often causes headaches and multiple cranial nerve palsies due to fibrous entrapment or ischemic damage. Although several etiologies, either infectious or autoimmune, have been suggested, most aspects of this rare disease remain to be elucidated. We report a case with the unusual and misleading features of multiple meningeal tumors occurring in a middle-aged immunodepressed woman with dysimmune status.

\section{Case report}

This 44-year-old Caucasian woman first came to medical attention in 1983 for a bilateral episcleritis pursuing an aggressive course, and eventually progressing towards scleromalacy. Initial therapy with oral methylprednisolone $8 \mathrm{mg}$ /day was complicated by bilateral cataract and was replaced with azathioprine 100 $\mathrm{mg} /$ day in 1989.

In 1984, she suffered an episode of lower limb erythroderma nodosa and tibio-tarsal arthritis with transient concomittant increase of anti-streptokinase and anti-streptolysin antibody titers, prompting a course of penicillin and salicylates. Other osteoarticular manifestations included metatarso-phalangeal synovitis in 1985 and calcaneitis in 1989. Exhaustive evaluation for systemic disease failed to disclose any other parenchymal involvement. The following laboratory studies were normal: complete blood count, erythrocyte sedimentation rate, C-reactive protein, serum and urine chemistry, immunoglobulins, C3-C4, and thyroid hormones. Serum antibody titers for Aspergillus, Chlamydia, Yersinia, Brucella, Salmonella and Treponema pallidum were negative. Angiotensin converting enzyme (ACE) titer was normal. Antinuclear antibody titer was positive at 1:320 with a homogenous and speckled pattern. The serum was negative for rheumatoid factor, anti-cardiolipin antibody, anti-ribonucleoprotein, anti-Smith, anti-double strand DNA, SS-A and SS-B. HLA-typing was A10A28 B12B18 CWO DR2 DR5.

In November 1993, she complained of left hearing loss, headaches and dizziness. Physical examination, including detailed neurological testing, was normal except for a left cochleovestibular deficit. Laboratory studies 
on serum and CSF were unrevealing. Brain computed tomography scan showed two infratentorial meningeal and one supratentorial tumor, which were isodense and intensively enhanced after contrast injection. These lesions appeared isointense on T1-weighted magnetic resonance imaging, intensively enhanced after gadolinium-DTPA administration (Fig. 1) and hypointense on T2-weighted sequences. They had a large implantation on the dura mater, without remodeling underlying bone structures. No diffuse thickening of the dura mater was observed. Carotid and vertebral angiography was normal and the tumors appeared poorly vascularized. A posterior fossa craniectomy was performed and the dural-based left nodule was almost totally resected; histopathology demonstrated a non-caseous necrotizing granulomatous pachymeningitis of unknown etiology. There was no vasculitis. Specific stains were negative for fungi and acid-fast bacilli. Subsequent evaluation for pathogens in CSF and serum samples remained negative.

Local recurrence and continuous growth of the other masses, despite immunosuppressive therapy with azathioprine $100 \mathrm{mg} /$ day, prompted a second resection performed on the supratentorial lesion in December 1995. This firm and homogeneously whitish 3-cm tumor was anchored on the dura mater and was well demarcated from leptomeninges by a smooth dome-shaped outline. Microscopic examination showed a dense fibrous tissue infiltrated by plasma cells, lymphocytes, polymorphs, eosinophils and histiocytes often organized in non-caseous necrotizing granulomas (Fig. 2). Specific stains and culture for bacteria and fungi on biopsy samples were unremarkable. Immunohistochemical studies of the plasma cell population for heavy and light chains of immunoglobu-lins demonstrated a polyclonal phenotype; immunostaining for protein S-100, vimentin and epithelial membrane antigen showed no meningothelial proliferation. A diagnosis of IHCP was proposed, with possible dysimmune etiology. Post-operative evolution was marked by the appearance of right hearing loss. The patient is currently treated with oral methylprednisolone $8 \mathrm{mg}$ daily and a monthly intravenous pulse of cyclophosphamide $500 \mathrm{mg} / \mathrm{m}^{2}$.

Fig. 1 A, B Cranial magnetic resonance imaging: T1-weighted image after gadolinium-DTPA injection. A Bilateral infratentorial meningeal tumor in the vicinity of jugular foramens. $\boldsymbol{B}$ Isointense supratentorial pterional meningeal mass
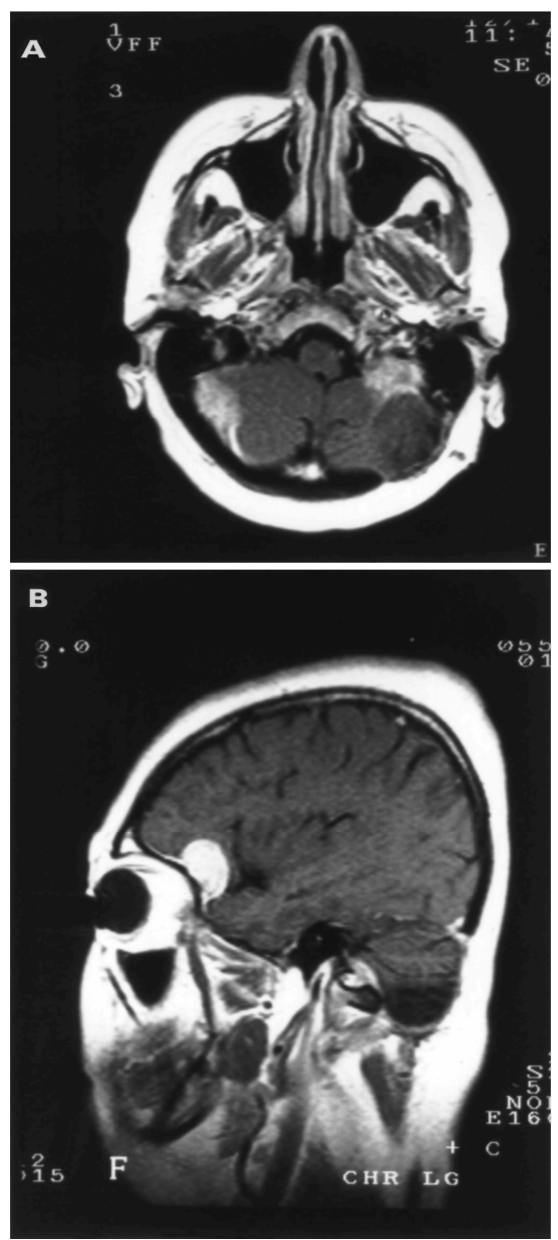
Fig. 2 A, B Biopsy specimen from the pterional mass. A Necrotizing granuloma with giant cells in a dense fibrous tissue infiltrated by polymorphs, eosinophils and plasma cells. $\boldsymbol{B}$ Necrotic areas are filled with pycnotic pleomorphs without caseous formation or fibrinoid deposition. A, B Hematoxylin, eosin and safran stain; $\boldsymbol{A} \times$ $85, \boldsymbol{B} \times 220$

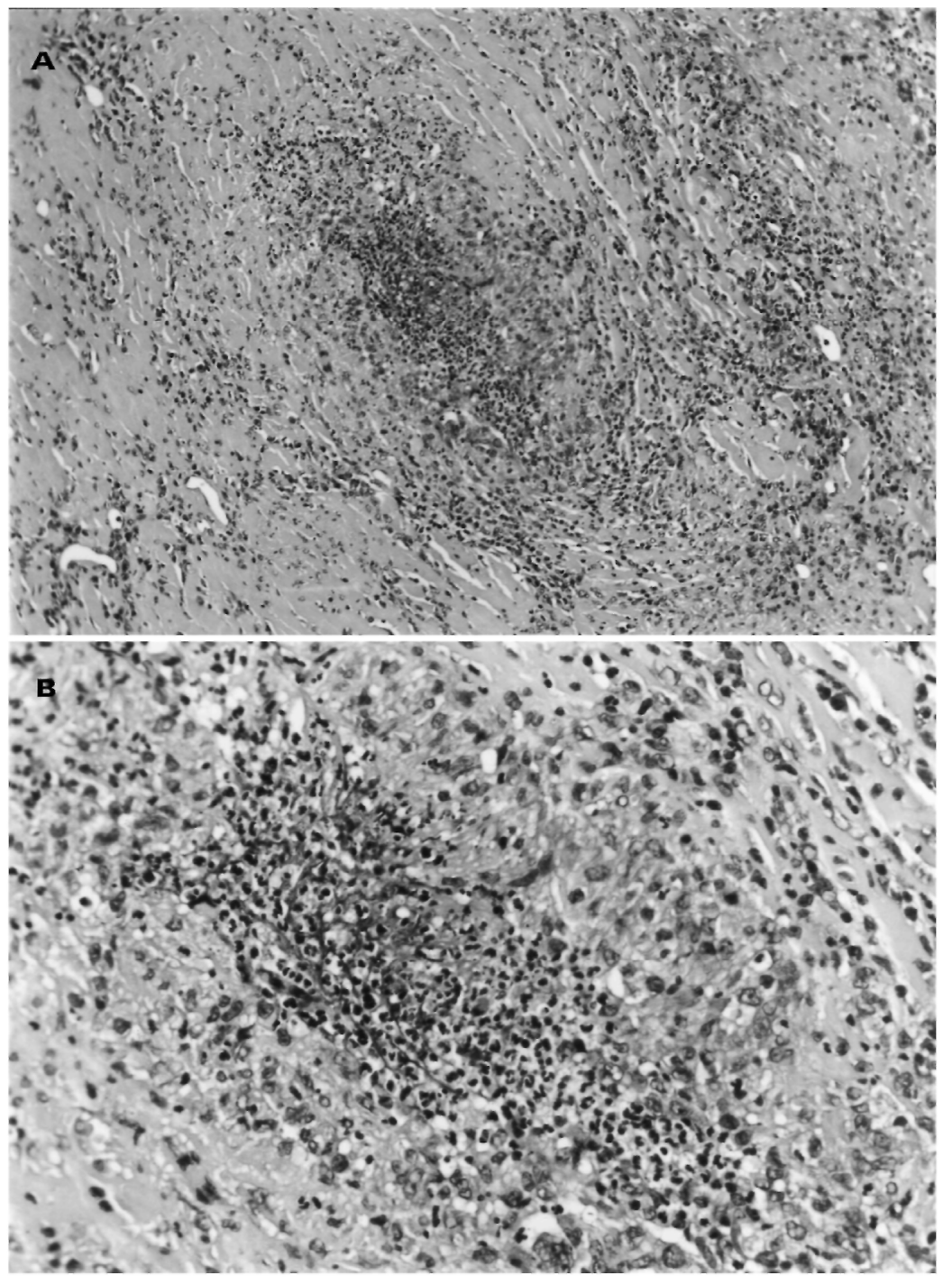

\section{Discussion}

Clinical, neuroimaging and histopathological findings of our case are consistent with those of IHCP except that dura mater involvement was not diffuse but nodular, mimicking multiple meningeal tumors.

Severe headaches and eighth cranial nerve pair dysfunction were the major clinical manifestations of our patient. Headache is a prominent symptom of IHCP, which is responsive to corticotherapy but not to CSF diversion. It most often reflects meningeal irritation by an inflammatory process rather than increased intracranial pressure; only three cases of IHCP-related hydrocephalus are reported in the literature [2]. Blindness caused by optic nerve compression, palsies of eighth, fifth, seventh and lower cranial nerves and cerebellar ataxia have also been reported $[2,17]$.

Recent progress in neuroimaging has given rise to an increase in the reporting of IHCP. Two major patterns of pachymeningeal hypertrophy are generally encountered: one located in the parasellar and cavernous regions, with entrapment of the cavernous and supraclinoidal segment of the internal carotid artery and optic nerves [15, 32]; and a second more frequent syndrome affecting the falcotentorial and clival dura mater with multiple cranial nerve involvement $[7,14]$. To the best of our knowledge, nodular pseudo-tumoral thickening of dura mater has 
been reported previously in only five cases of IHCP [16-18]. Lesions appeared isolated [16-18] or associated with diffuse thickening of falcotentorial pachymeninges [16, 18]. One case showed local recurrence [16]. Multiple synchronous meningeal tumors as a manifestation of IHCP have never been reported before and neuroradiological features of our case seem to be unique. Our observation and previous reports [16-18] lay emphasis on the necessity for considering IHCP as part of the differential diagnosis of meningeal tumors.

Histopathological features of IHCP encompass pachymeningeal fibrosis and an inflammatory infiltration of various cellular admixtures. Granulomas, whether necrotizing or not, have been reported occasionally [16]. In the case under discussion, the presence of uni-or multi-nucleated histiocytes organized in non-caseous necrotizing granulomas was a prominent feature. As previous authors, we can not explain the pathogenesis of the disease.

Bacterial (Treponema pallidum [6, 21], Mycobacterium tuberculosis [3, 19]) and fungal (Candida species [9], Aspergillus flavus [22], Petriellidum boydii [27]) infections have been reported to cause hypertrophic cranial pachymeningitis. Because this immunodepressed patient was at higher risk with regard to opportunistic infection, a broad range of tests for bacterial, fungal and protozoan pathogens was performed. Extensive evaluation of CSF, serum and biopsy specimens remained negative. The possibility of dural thickening accompanying otorhinolaryngological disease was also rejected on the basis of clinical and radiological features.

Central nervous system involvement in sarcoidosis may occur with hypertrophic pachymeningitis and mimick meningioma [26]. The fact that the patient's serum ACE titer was within normal range and the histological findings showed numerous necrotizing ganulomas did not favor such a diagnosis.

Meningeal inflammatory masses of the dura [20] constitute an heterogeneous group of uncertain etiology that has been reported under various names such as plasma cell granuloma [5, 20,31], hyalinizing plasmacytic granulomatosis [23] or inflammatory pseudo-tumour [5] because of their similarity to the lesions described in the lungs and other tissues [4]. The proportions of inflammatory and meningothelial components varied from case to case; some might have been true meningioma with a striking inflammatory component [11, 20], other were inflammatory masses with nests of trapped hyperplastic meningothelial cells. In all cases, inflammation was not accounted for by an infectious agent, a malignancy or a recognized systemic disorder. Inflammatory cells consisted predominantly of polyclonal plasma cells and lymphocytes with germinal center formation, and histiocytes associated with a various degree of fibrosis. No granulomas were described. The histopathological features of our case do not correspond to this entity as no meningothelial cells were seen and necrotizing granuloma were a common finding. Nevertheless, pseudotumoral IHCP and inflammatory pseudotumor might turn out to be various expressions of a same basic disorder. We searched for vasculitis lesions but could not find any neuroradiological or histological criteria in our patient.

Hypertrophic cranial pachymeningitis has been reported in association with systemic diseases such as rheumatoid arthritis [13, 28, 30,33], polyarteritis nodosa [1] and Wegener's granulomatosis [8, 24]. Our patient had a previous history of long-lasting rheumatic disease associating episcleritis, multiple peripheral arthritis and erythroderma nodosa. Laboratory findings showed a positive titer of antinuclear antibodies (ANA) at 1:320 and DR2 allel on HLA typing. These nonspecific manifestations do not fit the classification criteria for a specific systemic disorder as defined by the American College of Rheumatology, but clearly indicate a dysimmune status. An autoimmune or dysimmune mechanism in the pathogenesis of IHCP has been suggested previously for a patient associating IHCP, myocarditis with a high serum ANA titer [29] and in a recent report on IHCP occurring in HTLV-1-infected patients [12].

Optimal therapy relies on achievement of a better understanding of the pathogeny of IHCP. In the meanwhile, empiric trials have used radiotherapy, azathioprine and corticosteroids. A high dosage of oral methylprednisolone seems to be the most effective therapy but relapse frequently occurs when tapering the dosage. Spontaneous regression has also been reported [25]. Clearly, more reports with a longer follow-up are warranted before establishing the natural history of the disease and the efficacy of therapy.

\section{References}

1. Aström KE, Lidholm SO (1963) Extensive intracranial lesions in a case of orbital non-specific granuloma combined with polyarteritis nodosa. J Clin Pathol 16:137-143

2. Botella C, Orozco M, Navarro J, Riesgo P (1994) Idiopathic chronic hypertrophic craniocervical pachymeningitis: case report. Neurosurgery 35:1144-1149 
Published in : Acta Neuropathologica (1997), vol. 94, pp. 385-389.

Status : Postprint (Author's version)

3. Callebaut J, Dormont D, Dubois B, Chiras J, Bories J (1990) Contrast-enhanced MR imaging of tuberculous pachymeningitis cranialis hypertrophica: case report. AJNR 11:821-822

4. Dail DH, Hammar SP (1988) Pulmonary pathology. Springer, New York, pp 889-898

5. Eimoto T, Yanaka M, Kurosawa M, Ykeya F (1978) Plasma cell granuloma (inflammatory pseudo-tumor) of the spinal cord meninges. Cancer 41:1929-1936

6. Feringa ER, Weatherbee L (1975) Hypertrophic granulomatous cranial pachymeningitis causing progressive blindness in a chronic dialysis patient. J Neurol Neurosurg Psychiatry 38:1170-1176

7. Friedman D, Flanders A, Tartaglino L (1993) Contrast-enhanced MR imaging of idiopathic hypertrophic craniospinal pachymeningitis. AJR 160:900-901

8. Ghilain S, Delreux V, Kevers L, Sindic CJM, Mathurin P, Laterre EC (1988) Atteinte multiple des paires crâniennes associée à une pachyméningite tentorielle à caractère granulomateux. Acta Neurol Belg 88:91-100

9. Gorell JM, Palutke WA, Chason JL (1979) Candica pachymeningitis with multiple cranial nerve paresis. Arch Neurol 36 : $719-720$

10. Hassin GB, Zeitlin H (1940) Syphilitic cerebral hypertrophic pachymeningitis. Arch Neurol Psychiatry 43:362-371

11. Horten BC, Urich H, Stefoski D (1979) Meningiomas with conspicuous plasma cell-lymphocytic components. A report of five cases. Cancer 43:259-264

12. Kawano Y, Kira J (1995) Chronic hypertrophic cranial pachymeningitis associated with HTLV-I infection. J Neurol Neurosurg Psychiatry 59:435-437

13. Kepes JJ, Dunlap MD, Boynick PO, Terreros D (1986) Meningioma with multiple rheumatoid nodules. A case report. Acta Neuropathol (Berl) 70:314-319

14. Kioumehr F, Au A, Rooholamini SA, Yaghmai I, Verma R (1994) Idiopathic hypertrophic cranial pachymeningitis: a case report. Neuroradiology 36:292-294

15. Lam BL, Barrett DA, Glaser JS, Schatz NJ, Brown HH (1994) Visual loss from idiopathic intracranial pachymeningitis. Neurology 44:694-698

16. Mamelak AN, Kelly WM, Davis RL, Rosenblum ML (1993) Idiopathic hypertrophic cranial pachymeningitis. J Neurosurg 79:270-276

17. Martin N, Masson C, Henin D, Mompoint D, Marsault C, Nahum H (1989) Hypertrophic cranial-pachymeningitis: assessment with CT and MR imaging. AJNR 10:477-484

18. Masson C, Hénin D, Hauw JJ, Rey A, Raverdy P, Masson M (1993) Cranial pachymeningitis of unknown origin: a study of seven cases Neurology 43:1329-1334

19. Michel D, Girard DF, Tommasi M, Masson R, Trillet M, Piccinali JP (1969) Les pachyméningites granulomateuses intracrâniennes à symptomatologie pseudo-tumorale. J Med Lyon 50:545-577

20. Mirra SS, Tindall SC, Check IJ, Brynes RK, Moore WW (1983) Inflammatory meningeal masses of unexplained origin. An ultrastructural and immunological study. J Neuropathol Exp Neurol 42:453-468

21. Moore AP, Rolfe EB, Jones EL (1985) Pachymeningitis cranialis hypertrophica. J Neurol Neurosurg Psychiatry 48:942-944

22. Murai H, Kira J, Kobayashi T, Goto I, Inoue H, Hasuo K (1992) Hypertrophic cranial pachy-meningitis due to Aspergillus flavus. Clin Neurol Neurosurg 94:247-250

23. Nazek M, Mandybur TI, Sawaya R (1988) Hyalinizing plasmacytic granulomatosis of the falx. Am J Surg Pathol 12:308-313

24. Nishino H, Rubino FA, Parisi JE (1993) The spectrum of neurology involvement in Wegener's granulomatosis. Neurology 43:1334-1337

25. Nishio S, Morioka T, Togawa A, Yanase T, Nowata H, Fukui M, Hasuo K (1995) Spontaneous resolution of hypertrophic cranial pachymeningitis. Neurosurg Rev 18:201-204

26. Ranoux D, Devaux B, Lamy C, Mear JY, Roux FX, Mas JL (1992) Meningeal sarcoidosis, pseudo-meningioma, and pachymeningitis of the convexity. J Neurol Neurosurg Psychiatry 55:300-303

27. Schiess RJ, Goseia MF, Mc Clellan GA (1984) Petriellidium boydii pachymeningitis treated with miconazole and ketoconazole. Neurosurgery 14:220-224 
Published in : Acta Neuropathologica (1997), vol. 94, pp. 385-389.

Status : Postprint (Author's version)

28. Spurlock RG, Richman AV (1983) Rheumatoid meningitis. Arch Pathol Lab Med 107:129-131

29. Tanaka M, Suda M, Ishikawa Y, Fujitake J, Fujii H, Tatsuoka Y (1996) Idiopathic hypertrophic cranial pachymeningitis associated with hydrocephalus and myocarditis: remarkable steroid-induced remission of hypertrophic dura mater. Neurology 46:554-556

30. Weinstein GW, Powell SR, Thrush WP (1987) Chiasmal neuropathy secondary to rheumatoid pachymenigitis. Am J Ophthalmol $104: 439-440$

31. West SG, Pittman DL, Coggin JT (1980) Intracranial plasma cell granuloma. Cancer 46:330-335

32. Willing SJ, Broghamer W (1992) Internal caroitid artery occlusion due to idopathic cranial pachymeningitis. AJNR 13:1594-1596

33. Yuh WTC, Drew JM, Rizzo M, Ryals TJ, Sato Y, Bell WE (1990) Evaluation of pachy-meningitis by contrast-enhanced MR imaging in a patient with rheumatoid disease. AJNR 11:1247-1248 